\title{
PENGARUH KEWAJIBAN MORAL DAN LINGKUNGAN SOSIAL TERHADAP KEPATUHAN WAJIB PAJAK ORANG PRIBADI PENGUSAHA
}

\author{
Zahra Durah Nabila \\ Prodi Akuntansi Universitas Negeri Yogyakarta \\ nabillazahradurah@gmail.com \\ Dra. Isroah, M.Si. \\ Staf Pengajar Jurusan Pendidikan Akuntansi Universitas Negeri Yogyakarta
}

\begin{abstract}
Abstrak : Pengaruh Kewajiban Moral Dan Lingkungan Sosial Terhadap Kepatuhan Wajib Pajak Orang Pribadi Pengusaha. Penelitian ini bertujuan untuk mengetahui (1) Pengaruh Kewajiban Moral terhadap Kepatuhan Wajib Pajak. (2) Pengaruh Lingkungan Sosial terhadap Kepatuhan Wajib Pajak. (3) Pengaruh Kewajiban Moral dan Lingkungan Sosial terhadap Kepatuhan Wajib Pajak. Populasi dalam penelitian ini adalah Wajib Pajak Orang Pribadi Pengusaha di KPP Pratama Bantul sebanyak 19.398 Wajib Pajak dengan sampel sebanyak 200 Wajib Pajak. Data Penelitian ini diperoleh melalui kuesioner. dengan teknik pengambilan sampel insidental sampling. Hasil penelitian ini menunjukan (1) Kewajiban Moral berpengaruh positif dan signifikan terhadap Kepatuhan Wajib Pajak dengan nilai koefisien determinasi 0,734 (2) Lingkungan sosial berpengaruh positif dan signifikan terhadap Kepatuhan Wajib Pajak dengan koefisien determinasi 0,830 (3) Kewajiban moral dan Lingkungan Sosial berpengaruh positif dan signifikan terhadap Kepatuhan Wajib Pajak dengan nilai koefisien regresi 0,682 dan 0,306 nilai $F_{\text {hitung }}$ lebih besar dibandingkan dengan $F_{\text {tabel }}$ pada tingkat signifikansi $5 \%(179,323>3,04)$.
\end{abstract}

Kata kunci: Kepatuhan Wajib Pajak, Kewajiban Moral, Lingkungan Sosial

Abstract: The Effect Of Moral Obligation And Social Environment Towards Private Body Taxpayer Obedience Of Businessmen. This research was aimed to know the effect of (1) Moral Obligation towards private body taxpayer in tax service office of Bantul (2) Social Environment towards private body taxpayer in tax service office of Bantul (3) Moral obligation and Social Environment towards private body taxpayer in tax service office of Bantul. The research population were businessmen private body taxpayers in Tax Service Office Pratama of Bantul numbered 19,398 taxpayers. These research samples were 200 taxpayers by an incidental sampling sample taking technique. Data gathering method was by a questionnaire. The research results showed that (1) Moral Obligation positively and significantly affected taxpayer obedience. This was shown by a positive regression coefficient of 0.734 (2) Social Environment positively and significantly affected taxpayer obedience that was proven by a positive regression coefficient value i.e. 0.830 (3) Moral Obligation and Social Environment jointly positively and significantly affected obedience. This was proven by a positive regression coefficient value i.e. 0.682 and 0.306 and $F$ count value greater than $F$ table in significance 5\% (179.323 > 3.04).

Keywords: taxpayer obedience, moral obligation, social environment

\section{PENDAHULUAN}

Pajak menjadi fenomena yang menarik dan selalu berkembang di masyarakat mengingat pajak sebagai salah satu sumber pendapatan negara yang memiliki peranan yang besar dalam pembiayaan suatu negara demi mewujudkan kesejahteraan masyarakat. Penerimaan pajak di Indonesia tahun 2017 telah mencapai 1339,8 triliun atau mencapai $91 \%$ dari target yang dianggarkan (Kompas,2018). Target penerimaan negara dalam sektor 


\section{JURNAL NOMINAL / VOLUME VIII NOMOR I / TAHUN 2019}

perpajakan selalu diupayakan oleh pemerintah mengingat pentingnya peran pajak dalam mewujudkan kemajuan negara yang nantinya untuk mensejahterakan masyarakat. Pajak diperoleh dari kontribusi atau iuran wajib masyarakat kepada negaranya yang tidak mendapatkan timbal balik secara langsung dan bersifat memaksa namun sesuai dengan UndangUndang yang berlaku. Pemungutan pajak dilakukan dengan menggunakan Self Assesment System merupakan sistem pemungutan pajak yang memberikan kepercayaan kepada Wajib Pajak untuk menghitung, membayar dan melaporkan sendiri pajak terutangnya. Penerapan Self Assesment System akan bergantung dan efektif jika masyarakat (Wajib Pajak) menyadari kepatuhan sukarela dalam melaksanakan kewajiban perpajakannya. Di Daerah Istimewa Yogyakarta khususnya di Daerah Bantul kepatuhan pengusaha Bantul dalam membayar pajaknya masih rendah. Kepatuhan WPOP-Pengusaha di Bantul hanya sekitar $40 \%$ yang tertib pajak di Kantor Pelayanan Pajak Pratama Bantul (metrotvnews.com). Menurut data yang diperoleh dari KPP Pratama Bantul tahun 2016 tercatat jumlah WPOP-Pengusaha yang terdaftar sebanyak 19.398 Wajib Pajak. Namun, dari jumlah tersebut hanya 4.780 Wajib Pajak yang membayar pajaknya dan sebanyak 3.292 Wajib Pajak yang melakukan pelaporan SPT. Dengan demikian, dapat diketahui terdaftar di KPP Pratama Bantul masih rendah hal tersebut dilihat dari data yang diperoleh yang menunjukan terjadinya ketidakseimbangan antara jumlah Wajib Pajak yang terdaftar dengan jumlah Wajib Pajak yang membayar pajak dan dengan Wajib Pajak yang melapor SPT. Kepatuhan Wajib Pajak merupakan suatu keadaan di mana Wajib Pajak patuh dalam melaksanakan kewajiban perpajakannya untuk membayar pajaknya sesuai dengan ketentuan yang berlaku, melaporkan kewajiban pajaknya seuai dengan undang-undang yang berlaku, serta membayar pajaknya sesuai dengan ketentuan yang berlaku. Sebenarnya, permasalahan kepatuhan pajak timbul karena persepsi terhadap faktor didalam diri individu dan di luar diri individu. Kepatuhan Wajib Pajak dalam hal ini di nilai dalam ketaatannya memenuhi kewajiban perpajakannya baik dari segi formal dan meteril, kepatuhan tersebut dapat diidentifikasi dari kepatuhan WP dalam mendaftarkan diri, menyetorkan SPT, perhitungan dan pembayaran tunggakan (Bryan Wahyu Rahmanto,2015:7). Untuk mewujudkan Kepatuhan Wajib Pajak terhadap peraturan perpajakan diawali dari niat atau persepsi dalam diri individu dan luar diri individu (Ajzen dalam Prasetyo, Hamidah dan Fransisca 2015:2). Menurut Sherly dan Putu (2014) kewajiban moral dapat 


\section{JURNAL NOMINAL / VOLUME VIII NOMOR I / TAHUN 2019}

mempengaruhi tingkat Kepatuhan Wajib Pajak. Ajzen (2002:4) menyimpulan kewajiban moral merupakan moral yang berasal dari masing-masing individu yang kemungkinan orang lain tidak memilikinya. Saat ini kewajiban moral Wajib Pajak khususnya di Bantul belum mencapai tingkat yang diharapkan hal ini dapat dilihat dari pemasukan SPT yang belum maksimal. Di Kantor Pelayanan Pajak Pratama Bantul WPOP-Pengusaha yang melaporkan SPT sebesar 16\% dari jumlah Wajib Pajak yang terdaftar di KPPPratama Bantul. Kewajiban moral yang lebih kuat dari Wajib Pajak akan mampu meningkatkan tingkat kepatuhannya (Daniel Ho dalam Dicka Christha, 2016:3). Kepatuhan Wajib Pajak juga dapat dipengaruhi oleh lingkungan sosialnya karena lingkungan sosial merupakan salah satu faktor yang berasal dari luar diri Wajib Pajak dan menjadi salah satu faktor yang dapat mempengaruhi seseorang atau kelompok dalam melakukan suatu tindakan serta perubahan prilaku setiap individu. Lingkungan sosial merupakan orang/manusia yang mempengaruhi seseorang, baik pengaruh secara langsung maupun tidak langsung (Dalyono, 2001:133). Lingkungan sosial dapat memicu masyarakat untuk saling meniru, jika seseorang berada di lingkungan yang baik (taat aturan) akan mampu mempengaruhi Wajib Pajak untuk patuh terhadap kewajibannya (Lia Rahmi
Salam, 2015:27).Bayar pajak adalah kewajiban seluruh warga negara, terkecuali bagi mereka yang dibebaskan oleh peraturan perundang-undangan (onlinepajak.com). Saat ini WPOPPengusaha di Bantul masih ada yang melanggar aturan, hal tersebut diketahui karena masih adanya WPOP-pengusaha yang tidak membayar pajak. Pada tahun 2016 tercatat di Kantor Pelayanan Pajak Pratama Bantul WPOP-Pengusaha yang membayar pajak sebesar $24 \%$ dari jumlah Wajib Pajak yang terdaftar di Kantor Pelayanan Pajak Pratama Bantul. Masih adanya WPOP-pengusaha yang tidak membayar pajak memicu masyarakat lingkungan sekitarnya meniru untuk tidak mematuhi peraturan dengan tidak membayar pajak akibatnya jumlah WPOPpengusaha yang bayar pajak rendah. yang akhirnya berdampak pada realisasi penerimaan pajak yang tidak mencapai target. Berdasarkan hasil uraian dan fenomena yang terjadi di atas, penulis tertarik untuk melakukan penelitian dengan judul "Pengaruh Kewajiban Moral dan Lingkungan Sosial terhadap Kepatuhan Wajib Pajak Orang Pribadi Pengusaha pada Kantor Pelayanan Pajak Bantul”.

\section{METODE PENELITIAN}

\section{Desain Penelitian}

Jenis penelitian ini adalah penelitian kausal komperatif (causal comperativ research) 


\section{JURNAL NOMINAL / VOLUME VIII NOMOR I / TAHUN 2019}

yaitu penelitian yang bertujuan untuk menyelidiki kemungkinan hubungan sebab akibat (Sumadi Suryabrata, 2013:84). Pendekatan penelitian yang digunakan adalah pendekatan kuantitatif, karena dalam penelitian ini menggunakan data yang berupa angka. Pendekatan kuantitatif adalah metode penelitian yang digunakan untuk meneliti populasi atau sampel tertentu yang bertujuan untuk menguji hipotesis yang telah ditetapkan (Sugiyono, 2015:13). Objek penelitian yang diteliti adalah Wajib Pajak Orang Pribadi Pengusaha yang terdaftar di KPP Pratama Bantul. Data yang digunakan pada penelitian ini menggunakan data primer.

2. Tempat dan Waktu Penelitian

Penelitian ini dilaksanakan di Kantor Pelayanan Pajak (KPP) Pratama Bantul yang beralamat di Jl. Urip Sumohardjo No.7 Gose Bantul. Penelitian dilaksanakan pada bulan Maret 2018- April 2018.

3. Populasi dan Sampel Penelitian Populasi dalam penelitian ini adalah WP-OP pengusaha berjumlah 19.692 orang yang terdaftar di Kantor Pelayanan Pajak Bantul (KPP Pratama Bantul). Banyaknya populasi dalam penelitian ini maka penentuan jumlah sampel pada penelitian ini menggunakan teori pengambilan sampel dari Roscoe. Menurut Roscoe dalam Sugiyono (2015:131) “Ukuran sampel yang layak dalam penelitian adalah 30 sampai dengan 500, selain itu bila dalam penelitian akan melakukan analisis dengan multivariate (korelasi atau regresi), maka jumlah anggota sampel minimal 10 kali dari variabel yang diteliti”. Teknik pengambilan sampel pada penelitian ini menggunakan incidental sampling dengan jumlah sampel yang digunakan berdasarkan teori Rescoe sebanyak 200 responden atau 66 kali dari jumlah variabel yang diteliti, $(200 / 3)=66$.

\section{Teknik dan Instrumen Penelitian}

Teknik pengumpulan data dalam penelitian ini adalah dengan menggunakan angket/kuesioner. Instrumen yang digunakan dalam penelitian ini berupa angket yang bersifat tertutup, sehingga responden hanya perlu memberikan tanda checklist $(\sqrt{ })$ pada alternatif jawaban yang telah disediakan. Pengukuran variabel Kepatuhan Wajib Pajak, Kewajiban Moral, dan Lingkungan Sosial menggunakan skala Likert.

\section{Uji Coba Instrumen}

1) Uji Validitas

Instrumen yang valid berarti alat ukur yang digunakan untuk mendapatkan data (mengukur) itu valid atau dengan kata lain Instrumen tersebut dapat digunakan untuk mengukur apa yang seharusnya diukur (Sugiyono,2015:203). 


\section{JURNAL NOMINAL / VOLUME VIII NOMOR I / TAHUN 2019}

\begin{tabular}{llll}
\hline Variabel & Item & $\begin{array}{l}\text { Tidak } \\
\text { Valid }\end{array}$ & $\begin{array}{l}\text { Item } \\
\text { Valid }\end{array}$ \\
\hline $\begin{array}{l}\text { Kepatuhan } \\
\text { Wajib } \\
\text { Pajak }\end{array}$ & 21 & 4 & 17 \\
\hline $\begin{array}{l}\text { Kewajiban } \\
\text { Moral }\end{array}$ & 19 & - & 19 \\
\hline $\begin{array}{l}\text { Lingkungan } \\
\text { Sosial }\end{array}$ & 10 & - & 10 \\
\hline
\end{tabular}

Tabel 1. Uji Validitas (Sumber: Data Primer Diolah, 2018)

Hasil uji validitas menunjukkan bahwa terdapat 4 butir pernyataan yang tidak valid dan selanjutnya tidak dipakai dalam penelitian.

2) Uji Reliabilitas

Instrumen yang reliabel merupakan instrumen yang bila digunakan beberapa kali untuk mengukut objek yang sama akan menghasilkan data yang sama (Sugiyono, 2015:203).

\begin{tabular}{lll}
\hline Variabel & $\begin{array}{l}\text { Jumlah } \\
\text { item }\end{array}$ & $\begin{array}{l}\text { Cronbach's } \\
\text { Alpha }\end{array}$ \\
\hline $\begin{array}{l}\text { Kepatuhan } \\
\text { Wajib Pajak }\end{array}$ & 17 & 0,836 \\
\hline $\begin{array}{l}\text { Kewajiban } \\
\text { Moral }\end{array}$ & 19 & 0,915 \\
\hline $\begin{array}{l}\text { Lingkungan } \\
\text { Sosial }\end{array}$ & 10 & 0,753 \\
\hline
\end{tabular}

Tabel 2. Uji Reliabilitas (Sumber: Data Primer Diolah, 2018)

Berdasarkan tabel di atas, terlihat bahwa nilai Cronbach's Alpha > 0,6, sehingga semua instrumen tersebut bersifat reliabel.

\section{Teknik Analisis Data}

1) Uji Prasyarat Analisis

a) Uji Normalitas

Menurut Imam Ghozali (2011: 160)

"Uji normalitas bertujuan untuk menguji apakah dalam sebuah model regresi, variabel dependen, variabel independen atau keduanya mempunyai distribusi normal atau tidak".

b) Uji Linearitas

$$
\text { Iman Ghozali (2011: 166) }
$$

mendefinisikan "Uji linearitas digunakan untuk mengetahui hubungan antara variabel independen dan variabel dependen mempunyai hubungan yang linear secara signifikan atau tidak". Untuk mengetahui liniearitas data dapat digunakan dengan menggunakan uji test of linierity dengan taraf signifikansi 5\%, sehingga jika nilai signifikansi linearity lebih besar dari 0,05 maka data tersebut linear, jika dibawah 0,05 maka data tersebut tidak linear.

c) Uji Heteroskedastisitas

Menurut Imam Ghozali (2011: 139) "Uji heteroskedastisitas bertujuan menguji apakah dalam model regresi terjadi kesamaan variance dari residual satu pengamatan ke pengamatan yang lain. Model regresi yang baik adalah yang homoskesdatisitas atau tidak terjadi heteroskedastisitas".Untuk melakukan uji heterokedastisitas dilakukan dengan menggunakan uji park.

d) Uji Multikolinearitas

Menurut Imam Ghozali (2011: 105) "Uji multikolinieritas bertujuan untuk menguji apakah dalam persamaan regresi ditemukan adanya korelasi antara variabel bebas (independen). Model 


\section{JURNAL NOMINAL / VOLUME VIII NOMOR I / TAHUN 2019}

regresi yang baik seharusnya tidak terjadi korelasi di antara variabel independen". Uji multikolinearitas dapat diketahui dengan menggunakan dua cara yaitu melihat nilai tolerance dan lawannya Variance Inflasion Factor (VIF). Jika VIF < 10 dan nilai tolerance $>0,10$ maka tidak terjadi gejala multikolinieritas.

\section{Uji Hipotesis}

Pengujian hipotesis merupakan suatu prosedur yang akan menghasilkan suatu keputusan yaitu keputusan menerima atau menolak hipotesis yang sudah dirumuskan (Purwanto dan Sulistyawati, 2011:145146). Uji hipotesis bertujuan untuk mengetahui pengaruh variabel bebas terhadap variabel terikat.

\section{Analisis Regresi Linear Sederhana}

Analisis regresi sederhana digunakan untuk mengetahui pengaruh variabel bebas (X) yaitu Kewajiban Moral dan Lingkungan Sosial terhadap variabel terikat (Y) yaitu Kepatuhan Wajib Pajak. Analisis regresi linear sederhana digunakan untuk menguji hipotesis pertama, kedua dan ketiga. Untuk mencari dengan menggunakan persamaan regresi, mencari koefisien determinasi $\left(\mathrm{r}^{2}\right)$ dan mencari signifikansi koefisien korelasi dengan uji t.

\section{Analisis Regresi Linear Berganda}

Regresi linear berganda adalah suatu analisis yang digunakan secara bersamaan untuk meneliti dua variabel atau lebih variabel terhadap satu variabel terikat dengan skala interval, (Umi Nariwati, 2008:5). Analisis ini digunakan untuk meramalkan bagaimana keadaan variabel terikat ketika jumlah variabel bebasnya lebih dari satu. Analisis regresi linear berganda dalam penelitian ini digunakan untuk menguji hipotesis tiga. Untuk mencari dengan menggunakan persamaan regresi, mencari koefisien determinasi $\left(\mathrm{r}^{2}\right)$ dan mencari signifikansi koefisien korelasi dengan uji $\mathrm{F}$.

HASIL PENELITIAN DAN

\section{PEMBAHASAN}

\section{Analisis Deskriptif}

Analisis deskripsi data yang disajikan dalam penelitian ini meliputi Minimum, Maksimum, Mean (M), dan Standar Deviasi (SD).

\begin{tabular}{llllll}
\hline Variabel & N & Min & Max & M & SD \\
\hline $\begin{array}{l}\text { Kepatuhan } \\
\text { Wajib }\end{array}$ & 200 & 43 & 68 & 57,8 & 5,9 \\
Pajak & & & & & \\
\hline $\begin{array}{l}\text { Kewajiban } \\
\text { Moral }\end{array}$ & 200 & 50 & 75 & 63,2 & 6,4 \\
\hline $\begin{array}{l}\text { Lingkungan } \\
\text { Sosial }\end{array}$ & 200 & 24 & 40 & 34,6 & 3,0 \\
\hline
\end{tabular}

Tabel 3. Hasil Analisis Deskriptif (Sumber:

Data Primer Diolah, 2018)

Selanjutnya setelah data diketahui, kemudian berdasarkan data tersebut dapat diketahui kecenderungan data responden. 


\section{JURNAL NOMINAL / VOLUME VIII NOMOR I / TAHUN 2019}

\section{Uji Prasyarat}

1) Uji Normalitas

Berdasarkan hasil uji normalitas pada menunjukkan nilai KolmogorovSmirnov $Z$ sebesar 0,856 dengan nilai signifikansi Asymp. Sig. (2-tailed) 0,456 sehingga dari hasil tersebut dapat diketahui bahwa nilai signifikansi yaitu $0,456>0,05$. Jadi dapat disimpulkan bahwa nilai residual dari data pada penelitian ini berdistribusi normal.

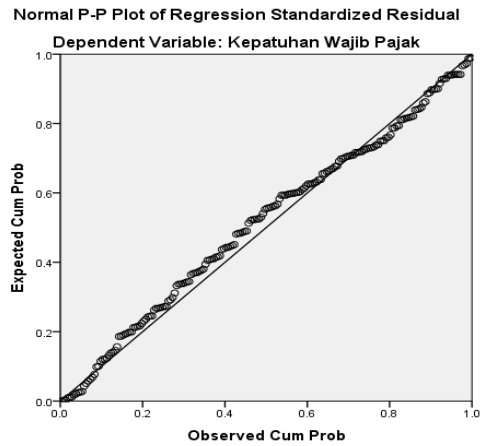

Gambar 1. Grafik Normal Plot

Dari hasil uji normalitas tersebut, menunjukkan bahwa terlihat titik-titik menyebar disekitar garis diagonal dan mengikuti arah garis diagonal, sehingga dapat disimpulkan bahwa data pada penelitian ini berdistribusi normal.

2) Uji Linearitas

Uji liniearitas dilakukan untuk mengetahui hubungan antara variabel bebas dan variabel terikat bersifat linear atau tidak.

\begin{tabular}{lcl}
\hline No. & Variabel & $\begin{array}{l}\text { Deviation } \\
\text { from } \\
\text { Linearity }\end{array}$ \\
\hline 1. & $\mathrm{Y}^{*} \mathrm{X}_{1}$ & 0,063 \\
\hline 2. & $\mathrm{Y}^{*} \mathrm{X}_{2}$ & 0,176 \\
\hline
\end{tabular}

Tabel 4. Hasil Uji Linearitas (Sumber:

Data Primer Diolah, 2018)

Berdasarkan tabel tersebut, dapat diketahui bahwa nilai signifikansi seluruh korelasi variabel $\mathrm{Y}^{*} \mathrm{X}>0,05$ sehingga dapat disimpulkan bahwa pengaruh masing-masing variabel independen terhadap variabel dependen bersifat linear.

3) Uji Multikolinearitas

Uji multikolinearitas bertujuan untuk menguji ada tidaknya korelasi antar variabel bebas.

\begin{tabular}{llll}
\hline \multirow{2}{*}{ No } & Variabel & $\begin{array}{l}\text { Collinearity } \\
\text { Statistic }\end{array}$ \\
\cline { 3 - 4 } & & Tollerance & VIF \\
\hline $\mathbf{1}$ & $\mathrm{X}_{1}$ & 0,871 & 1,149 \\
$\mathbf{2}$ & $\mathrm{X}_{2}$ & 0,871 & 1,149 \\
\hline
\end{tabular}

Tabel 5. Hasil Uji Multikolinearitas (Sumber: Data Primer Diolah, 2018)

Berdasarkan hasil perhitungan di atas nilai tolerance menunjukkan tidak ada variabel independen yang memiliki nilai tolerance kurang dari 0,10 . Selain itu, hasil perhitungan nilai Variance Inflation Factor (VIF) tidak lebih dari 10. Jadi dapat disimpulkan bahwa tidak ada multikolinearitas antar variabel independen dalam model regresi.

4) Uji Heterokedastisitas

Uji heteroskedastisitas bertujuan untuk menguji apakah dalam model regresi terjadi 
ketidaksamaan variance dari residuan satu pengamatan ke pengamatan yang lain.

\begin{tabular}{lll}
\hline No. & Model & Sig. \\
\hline $\mathbf{1}$ & $\mathrm{X}_{1}$ & 0,552 \\
\hline $\mathbf{2}$ & $\mathrm{X}_{2}$ & 0,651 \\
\hline
\end{tabular}

Tabel 6. Hasil Uji Heterokedastisitas (Sumber: Data Primer Diolah, 2018)

Berdasarkan tabel di atas dapat dilihat bahwa semua nilai signifikansinya lebih dari 0,05 , sehingga dapat disimpulkan bahwa tidak terjadi heteroskedastisitas dalam model regresi ini.

\section{Hasil Uji Hipotesis}

Teknik analisis regresi sederhana digunakan untuk menguji hipotesis pertama dan kedua. Selanjutnya untuk uji hipotesis ketiga yaitu menggunakan analisis regresi berganda.

\section{H1: Pengaruh Kewajiban Moral terhadap Kepatuhan Wajib Pajak.}

Ringkasan hasil analisis regresi sederhana untuk hipotesis pertama dalam penelitian ini adalah sebagai berikut:

\begin{tabular}{lllll}
\hline $\begin{array}{l}\text { Kons } \\
\text { Tanta }\end{array}$ & $\begin{array}{l}\text { Koef. } \\
\text { reg. }\end{array}$ & $\mathbf{r}^{\mathbf{2}}$ & $\mathbf{t}_{\text {hitung }}$ & Sig. \\
\hline $\mathbf{1 1 , 3 6 7}$ & 0,734 & 0,625 & 18,152 & 0,000 \\
\hline
\end{tabular}

Tabel 7. Analisis Regresi H1 (Sumber: Data Primer Diolah, 2018)

Berdasarkan hasil regresi di atas, maka dapat ditentukan persamaan garis regresi untuk hipotesis 1 yaitu:

$$
Y=11,367+0,734 X
$$

Persamaan di atas menunjukkan bahwa jika nilai $\mathrm{X}_{1}$ dianggap konstan maka
Kepatuhan Wajib Pajak akan tetap sebesar 11,367. Jika nilai $X_{1}$ naik 1 satuan maka $Y$ naik sebesar 0,734. Nilai koefisien determinasi $\left(\mathrm{r}^{2}\right)$ sebesar 0,625 yang menunjukkan bahwa Kepatuhan Wajib Pajak dipengaruhi oleh Kewajiban Moral $62,5 \%$, sedangkan sebanyak 37,5\% dipengaruhi oleh faktor lain. Nilai t hitung sebesar 18,152 lebih besar t tabel 1,972 dan signifikansi 0,000 yang berarti lebih kecil dari 0,05 menunjukkan Kewajiban Moral berpengaruh signifikan terhadap Kepatuhan Wajib Pajak. Dengan demikian, dapat disimpulkan bahwa Kewajiban Moral berpengaruh positif dan signifikan terhadap Kepatuhan Wajib Pajak, sehingga hipotesis diterima.

\section{H2: Pengaruh Lingkungan Sosial} terhadap Kepatuhan Wajib Pajak.

Ringkasan hasil analisis regresi sederhana untuk hipotesis kedua dalam penelitian ini adalah sebagai berikut:

\begin{tabular}{ccccc}
\hline $\begin{array}{c}\text { Kons } \\
\text { Tanta }\end{array}$ & $\begin{array}{c}\text { Koef } \\
\text { reg. }\end{array}$ & $\mathbf{r}^{2}$ & $\mathbf{t}_{\text {hitung }}$ & Sig. \\
\hline $\mathbf{2 9 , 0 9 9}$ & 0,830 & 0,175 & 6,491 & 0,000 \\
\hline Tabel 8 & Hasil & Uji Hipotesis 2 & (Sumber.
\end{tabular}

Tabel 8. Hasil Uji Hipotesis 2 (Sumber: Data Primer Diolah, 2018)

Berdasarkan hasil regresi di atas, maka dapat ditentukan persamaan garis regresi untuk hipotesis 2 yaitu:

$$
Y=29,099+0,830 X
$$

Persamaan di atas menunjukkan bahwa jika nilai $\mathrm{X}_{2}$ dianggap konstan maka Kepatuhan Wajib Pajak akan tetap sebesar 29,099. Jika nilai $X_{2}$ naik 1 satuan maka $Y$ 


\section{JURNAL NOMINAL / VOLUME VIII NOMOR I / TAHUN 2019}

akan naik sebesar 0,830 . Nilai korelasi $\left(\mathrm{r}^{2}\right)$ sebesar 0,175 yang menunjukkan bahwa Kepatuhan Wajib Pajak dipengaruhi oleh Lingkungan Sosial sebesar 17,5\%, sedangkan sebanyak $82,5 \%$ dipengaruhi oleh faktor lain. Nilai t hitung sebesar 6,491 lebih besar t tabel 1,972 dan signifikansi 0,000 yang berarti lebih kecil dari 0,05 menunjukkan Lingkungan Sosial berpengaruh positif dan signifikan terhadap Kepatuhan Wajib Pajak. Dengan demikian, dapat disimpulkan bahwa Lingkungan Sosial berpengaruh positif dan signifikan terhadap Kepatuhan Wajib Pajak, sehingga hipotesis diterima.

\section{H3: Pengaruh Kewajiban Moral dan} Lingkungan Sosial terhadap Kepatuhan Wajib Pajak.

Berdasarkan hasil analisis regresi berganda untuk hipotesis ketiga dalam penelitian ini adalah sebagai berikut:

\begin{tabular}{lll}
\hline Variabel & & \\
& $\mathbf{B}$ & Sig. \\
\hline Constant & 4,034 & - \\
\hline $\mathbf{X}_{\mathbf{1}}$ & 0,682 & 0,000 \\
\hline $\mathbf{X}_{\mathbf{2}}$ & 0,306 & 0,000 \\
\hline
\end{tabular}

\begin{tabular}{ll}
\hline $\mathbf{R}^{\mathbf{2}}$ & $\mathbf{F}_{\text {hitung }}$ \\
\hline $\mathbf{0 , 6 4 5}$ & 179,323
\end{tabular}

Tabel 9. Hasil Uji Hipotesis 3 (Sumber: Data Primer Diolah, 2018)

Berdasarkan regresi di atas, maka dapat ditentukan persamaan garis regresi untuk hipotesis 3 yaitu:

$$
Y=4,034+0,682 X_{1}+0,306 X_{2}
$$

Persamaan di atas menunjukkan bahwa jika seluruh nilai $\mathrm{X}$ dianggap konstan maka Kepatuhan Wajib Pajak (Y) sebesar 4,034. Jika nilai $\mathrm{X}_{1}$ naik 1 satuan maka nilai Y naik 0,682. Jika nilai $\mathrm{X}_{2}$ naik 1 satuan maka $\mathrm{Y}$ naik sebesar dan jika nilai $\mathrm{X}_{3}$ naik 1 satuan maka Y naik 0,306.

Nilai determinasi $R_{y_{(1,2)}}^{2}$ sebesar 0,645 yang menunjukkan bahwa Kepatuhan Wajib Pajak dipengaruhi oleh Kewajiban Moral dan Lingkungan Sosial sebesar $64,5 \%$, sedangkan $35,5 \%$ dipengaruhi oleh faktor lain. Hasil uji $\mathrm{F}$ hitung sebesar 179,323 dan F tabel sebesar 3,04 dan nilai signifikansi 0,000 untuk Kewajiban Moral dan Lingkungan Sosial yang berarti nilai signifikansi yang dihasilkan lebih kecil dari 0,05 menunjukkan bahwa Kewajiban Moral dan Lingkungan Sosial berpengaruh secara signifikan terhadap Kepatuhan Wajib Pajak, sehingga hipotesis diterima.

\section{SIMPULAN DAN SARAN}

\section{Simpulan}

Berdasarkan hasil pengujian dan pembahasan, dapat ditarik kesimpulan sebagai berikut:

1) Terdapat pengaruh positif dan signifikan Kewajiban Moral terhadap Kepatuhan Wajib Pajak Orang Pribadi Pengusaha (WP-OP Pengusaha) di KPP Pratama Bantul. 


\section{JURNAL NOMINAL / VOLUME VIII NOMOR I / TAHUN 2019}

Hal ini dapat dilihat dari nilai koefisien regresi sebesar 0,734 dan $t_{\text {hitung }}$ lebih besar dari $t_{\text {tabel }}(18,152>$ 1,97208) pada signifikansi 5\% serta nilai signifikansi Kewajiban Moral terhadap Kepatuhan Wajib Pajak lebih kecil dari nilai signifikansi ( $0,000<0,05)$.

2) Terdapat pengaruh positif dan signifikan Lingkungan Sosial terhadap Kepatuhan Wajib Pajak Orang Pribadi Pengusaha (WP-OP Pengusaha) di KPP Pratama Bantul. Hal ini dapat dilihat dari nilai koefisien regresi yang bernilai positif yaitu 0,830 dan nilai thitung lebih besar dari tabel $(6,491>$ 1,97208) pada signifikansi 5\% serta nilai signifikansi Lingkungan Sosial Wajib Pajak terhadap Kepatuhan Wajib Pajak lebih kecil dari nilai signifikansi $(0,000<0,05)$.

3) Terdapat pengaruh positif dan signifikan Kewajiban moral dan Lingkungan sosial secara bersama sama terhadap Kepatuhan Wajib Pajak Orang Pribadi Pengusaha (WP-OP Pengusaha) di KPP Pratama Bantul. Hal ini dapat dilihat dari nilai koefisien regresi yang bernilai positif yaitu 0,682 ; 0,306 dan nilai $F_{\text {hitung lebih besar }}$ dari $F_{\text {tabel }}(179,323>3,04)$ pad signifikansi $5 \%$. Selain itu nilai signifikansi kewajiban moral dan lingkungan sosial Wajib Pajak lebih kecil dari nilai $\alpha=5 \%(0,000<0,05)$.

\section{Saran}

Berdasarkan hasil dan kesimpulan penelitian yang sudah dibahas peneliti, selanjutnya dapat diusulkan beberapa saran sebagai berikut:

1) Menekankan pentingnya dukungan keluarga dan masyarakat untuk patuh terhadap kewajiban perpajakannya dengan mendukung para Wajib Pajak dalam melaksanakan/menyelesaikan

kewajiban perpajakannya. Hal tersebut dapat dioptimalkan dengan mengikuti penyuluhan atau sosialisasi mengenai manfaat pajak yang diadakan oleh instansi terkait yang ditujukan kepada semua Wajib Pajak. Selain itu, peran Dirjen Pajak sangat diperlukan guna meningkatkan kepercayaan masyarakat dengan cara mengikis habis oknum pajak yang tidak bertanggung jawab atau yang melakukan kecurangan-kecurangan dalam proses pemenuhan kewajiban perpajakannya agar Wajib Pajak tidak melakukan penghindaran kewajiban perpajakannya dan masyarakat tidak ragu dan bangga menjadi pembayar pajak. 
2) Bagi peneliti selanjutnya yang tertarik untuk melakukan kajian dibidang yang sama hendaknya dapat menambah variabel independen maupun dependen yang memiliki keungkinan pengaruh terhadap hubungan kewajiban moral, lingkungan sosial dan kepatuhan pajak atau dapat menggunakan variabel lain yang tidak digunakan dalam penelitian ini sehingga dapat ditemukan variabel baru yang dapat mempengaruhi tingkat Kepatuhan Wajib Pajak.

\section{DAFTAR PUSTAKA}

Andrianto, Risky.2017." Kepatuhan Pengusaha Bantul Bayar Pajak Rendah". http://www.metrotvnews.com. Diakses pada 26 juli 2017

Dalyono, M. 2001. Psikologi Pendidikan. Jakarta: PT. Rineka Cipta.

Febrinda, K,D,C (2016). Pengaruh Kewajiban Moral, Kualitas Pelayanan, Pemeriksaan Pajak, dan Sanksi Perpajakan, pada Kepatuhan Wajib Pajak Pribadi di KPP Jepara.Skripsi. Program Sarjana Fakultas Ekonomika dan Bisnis Universitas Dian Nuswantoro.

Julianto, Pramidia Arhando.2017. "Penerimaan Perpajakan 2017 Capai Rp 1.339 Triliun". https://ekonomi.kompas.com. Diakses pada 26 januari 2018.
Layata, S. \& Setiawan, P.E., 2014. Pengaruh Kewajiban Moral, Kualitas Pelayanan, Pemeriksaan Pajak dan Sanksi Perpajakan Pada Kepatuhan Wajib Pajak Badan. EJurnal Akuntansi Universitas Udayana, 9(2), pp.540- 556.

Minarto, P.R.A., Utami, H.N. \& Yaningwati, F. (2015).Pengaruh Karakteristik Individu Budaya dan Lingkungan Sosial Terhadap Kepatuhan Pemenuhan Perpajakan (Studi Pada WPOP di KPP Pratama Malang Utara). S1 (Volume 5 No. 1April 2015), Universitas Brawijaya.

Purwanto, Erwan Agus dan Dyah Ratih Sulityatuti. 2011. Metode Penelitian Kuantitatif, Edisi Pertama. Cetakan Kedua. Gava Gramedia : Yogyakarta.

Salam, Lia Rahmi (2015). Pengaruh Tax Compliance Costs Wajib Pajak Badan dan Tax Service Quality Terhadap Tindakan Tax Evasion. Skripsi. Program Sarjana Fakultas Ekonomi Universitas Widyatama.

Siahaan, Surtan. “ Ini Sanksinya Jika Anda Tidak Melakukan Pembayaran Pajak". $\quad$ https://www.onlinepajak.com. Diakses pada tanggal 07 januari 2018

Rahmanto Wahyu,Bryan. 2014. Pengaruh Pemahaman Peraturan Pajak, Sanksi Denda, Dan Kesadaran Wajib Pajak, Terhadap Kepatuhan Wajib Pajak Orang Pribadi Di Kantor Pelayanan Pajak Pratama Yogyakarta. Universitas Negeri Yogyakarta.

Ghozali, Imam. (2013). Aplikasi Analisis Multiviat dengan Program SPSS. Jakarta: Universitas Diponegoro Edisi IV. 
JURNAL NOMINAL / VOLUME VIII NOMOR I / TAHUN 2019

Sugiyono. (2015). Metode Penelitian Bisnis (Pendekatan Kuantitatif, Kualitatif dan $R \& D)$. Bandung: Alfabeta. 